Белоусова О.В.,
Белоусов Е.A.,
Дорохова Н.Н.

Федеральное государственное автономное образовательное учреждение высшего образования «Белгородский государственный национальный исследовательский университет» (НИУ «БелГУ»), ул. Победы, 85, г. Белгород, 308015, Россия. E-mail:belousova_e@bsu.edu.ru

\title{
Аннотация
}

В данной статье представлены результаты фармакоэкономического исследования ассортимента лекарственных препаратов для лечения стоматита на локальном аптечном рынке.

Стоматит - собирательное название заболеваний слизистой оболочки полости рта, разнообразных по причине возникновения и клиническим проявлениям.

В основу классификации стоматита положены различные признаки:

1) по клиническому течению:

- острые;

- хронические.

2) по характеру морфологических изменений:

- первичные (катаральное, фибринозное, альтернативное и пролиферативное воспаление);

- вторичные (эрозии, афты, язвы, пятна, рубцы).

3) по причине возникновения:

- повреждения, возникающие вследствие механической, физической и химической травмы (ссадина, афта Беднара, лучевые, химические и термические ожоги);

- заболевания, возникающие вследствие инфекций: вирусных (герпетический, коревой, ветряночный стоматит), бактериальных (стрептококковый, скарлатинозный, туберкулезный, гонорейный стоматит), грибковых (молочница, хронический кандидозный стоматит), спирохет и фузоспириллезной флоры (сифилис, язвенно-некротический стоматит Венсана);

- заболевания, возникающие вследствие аллергических реакций при контактной, микробной и лекарственной аллергии;

- изменения слизистой оболочки полости рта при некоторых системных заболеваниях и болезнях обмена.

4) по природе поражения:

- стоматит языка;

- язвенный стоматит;

- стоматит десен;

- стоматит горла;

- стоматит катаральный;

- везикулярный стоматит;

- протезный стоматит.

Опасность воспалительных заболеваний ротовой полости состоит в том, что на начальных стадиях они почти не имеют симптоматики, потому что почти не оказывают болевых ощущений. Пародонтит и гингивит являют собой до $97 \%$ всех заболеваний ротовой полости. То есть пародонт представляет собой ткани, окружающие зуб, точнее их комплекс. Его состав - это десна, перицемент, альвеолярная кость и в целом зуб. Медицинский термин „пародонт” определяет генетическое и функциональное единство тканей, которые окружают зуб [8, 17, 22].

Ключевые слова: стоматит; локальный аптечный рынок; фармакоэкономический анализ; фармацевтическое консультирование. 
Belousova O.V., Belousov Ye.A., Dorokhova N.N.

\section{THE APPLICATION OF PHARMACOECONOMIC METHODS TO OPTIMIZE PROCUREMENT OF MEDICINES FOR STOMATITIS IN PHARMACIES}

Medical Institute, Belgorod State National Research University, 85 Pobedy St., Belgorod, 308015, Russia E-mail:belousova_e@bsu.edu.ru

\begin{abstract} and clinical manifestations.

1) by clinical course:

- acute;

- chronic

3 ) due to the occurrence: metabolism.

4) the nature of the lesion:

- stomatitis of the tongue;

- ulcerative stomatitis;

- stomatitis of the gums;

- stomatitis of the throat;

- catarrhal stomatitis;

- vesicular stomatitis;

- prosthetic stomatitis.
\end{abstract}

The article presents the results of a pharmacoeconomic study of assortment of medicinal preparations for the treatment of stomatitis on the local pharmaceutical market.

Stomatitis is a collective name of diseases of the mucosa of the oral cavity, a variety of the cause

The classification of stomatitis is based on various symptoms:

2) the nature of morphological changes

-initial (catarrhal, fibrinous, alternative and proliferative inflammation

- secondary (erosion, aphthae, ulcers, blemishes, scars).

- damage resulting from mechanical, physical and chemical injury (abrasion, AFTA Bednar, radiation, chemical and thermal burns);

- disease caused by infections: viral (herpes, measles, varicellous thrush), bacterial (streptococcal, scarlet fever, tuberculous, gonorrheal stomatitis), fungal (thrush, chronic oral thrush), spirochaetes and fusospirochetal flora (syphilis, ulcerative-necrotic stomatitis Vincent);

- diseases caused by allergic reactions at contact, microbial and drug allergies;

- changes of the mucous membrane of the oral cavity in some systemic diseases and diseases of

The risk of inflammatory diseases of the oral cavity is in the fact that in the early stages of development, they are virtually asymptomatic, because they do not cause any pain. According to statistics, gingivitis (inflammation of the gums) and periodontitis (inflammation of the structures of the periodontal ligament and bone, alveolar bone) account for $94-96 \%$ of all periodontal diseases. The periodontium is a complex of tissues that surround the tooth and provide a reliable fixing it in the jaw bones: gums, periodontal ligament fibers, the surface layer of the cement of the roots of the teeth and bones of alveolar processes of the jaw [8, 17, 22].

Keywords: stomatitis; the local pharmaceutical market; pharmacoeconomic analysis; pharmaceutical business.

Введение. Самыми частыми причинами стоматита являются: отрицательное влияние грубой пищи на слизистую оболочку полости рта. Такой стоматит проходит самостоятельно через несколько дней; термическое повреждение пищей легко проходит, а вот аллергические реакции, связанные с продуктами, косметическими средствами (в этом случае стоматит имеет либо затяжное течение, либо постоянно рецидивирует).
Обследование у врача поспособствует определить источник аллергии и вылечить больного от стоматита. Стоматит часто проявляется у астматиков, использующих для лечения ингаляторы с кортикостероидами $[14,15,16,30]$.

Механизмы возникновения стоматитов, к сожалению, еще не выявлен полностью, поэтому причиной заболевания может быть все что угодно. К примеру, микроорганизмы-возбудители 
инфекции, воздействующие непосредственно на слизистую оболочку рта, болезни желудочнокишечного тракта, сердечно-сосудистой системы, общее ослабление иммунитета, авитаминоз, нарушения обмена веществ, нервные нарушения, злокачественные опухоли, гормональные колебания, анемия, различные травмы в виде ссадин слизистой оболочки рта и наследственность. Кроме того, причиной возникновения стоматитов могут являться местные факторы. Элементарное несоблюдение гигиены полости рта, кариес, дисбактериоз полости рта, некачественно сделанные или плохо установленные зубные протезы, последствия применения медикаментов, употребление никотина и алкоголя, а также аллергические реакции на продукты. Особо хочется сказать об использовании зубных паст, содержащих лаурилсульфат натрия. Различные исследования доказали, что они могут провоцировать возникновение стоматита и его обострение [18, 19, 29].

Большое количество микробов в то числе и грибы рода Candida находится в полости рта людей. При ухудшении местного иммунитета, связанного чаще всего с системными проявлениями болезней макроорганизма, воздействие этих микроорганизмов может стимулировать воспалительно-разрушительные повреждения ротовой полости [9]. Ротовая полость - это среда с высоким риском развития септических процессов. Тем не менее, в норме, существует равновесие между находящейся в них патогенной микрофлорой и местными и общими факторами защиты (иммунной, биологической, рефлекторной и т.д.). Нарушение этого равновесия может привести к развитию инфекционных и воспалительных заболеваний (стоматит) [7, 21, 23].

При катаральном стоматите воспаление затрагивает только самую поверхностную часть слизистой оболочки. Это поражение наиболее часто встречается особенно у лиц, не соблюдающих гигиену полости рта. Нередко причиной катарального стоматита бывают зубные отложения, болезни зубов, дисбактериоз ротовой полости, заболевания желудочно-кишечного тракта (гастрит, дуоденит, колит) или глистная инвазия. При катаральном стоматите наблюдаются болезненность слизистой оболочки рта, ее гиперемия, отечность, иногда - белый или желтый налет, неприятный запах изо рта [24, $25,31]$.
При язвенном стоматите воспаление распространяется на глубокие отделы, поражая всю толщину слизистой. Это более тяжелое заболевание, которое может возникнуть самостоятельно или быть запущенной формой катарального стоматита. Язвенный стоматит чаще развивается у больных, страдающих язвенной болезнью желудка или хроническим энтеритом. Нередко он встречается и при заболеваниях сердечно-сосудистой системы и крови, инфекциях и отравлениях. По клиническим признакам язвенный стоматит в начале заболевания на катаральный, но в дальнейшем отмечается повышение температуры тела до субфебрильных значений, появляются слабость, головная боль, увеличиваются и становятся болезненными региональные лимфатические узлы $[1,14,24]$.

При афтозном стоматите на слизистой оболочке образуются единичные или множественные мелкие дефекты - афты округлой или овальной формы с четкими границами, в виде узкой красной каймы и серовато-желтым налетом в центре. Чаще афтозный стоматит развивается при аллергических реакциях, вирусных инфекциях, болезнях желудочнокишечного тракта, ревматизме. Такой стоматит начинается с общего недомогания, повышения температуры тела, боли в местах образования афт. Если стоматит возникает довольно часто и долго не проходит, нужна помощь стоматолога. Чтобы сократить сроки болезни до минимума, необходимо придерживаться механически и химически щадящей диеты, нельзя употреблять слишком горячую пищу. Обязательна тщательная гигиена ротовой полости, поскольку патогенные бактерии, размножающиеся на остатках пищи, осложняют его течение. При аллергическом стоматите обязательно исключают контакт с аллергеном [2, 26,27,28].

Герпетический стоматит имеет ряд особенностей. Сначала участок слизистой оболочки краснеет, затем на нем возникают мелкие пузырьки (везикулы) с прозрачным содержимым. Везикулы через 2-3 дня лопаются, обнажая красноватую, отечную, зудящую поверхность. Герпетический стоматит обычно лечат противовирусными и иммунокорригирующими препаратами. Если вместе с симптомами стоматита возникает слабость, повышается температура тела, следует обязательно проконсультировать больного у специалиста, так как это может быть началом системного заболевания. К сожалению, стоматит 
возникает не только у взрослых, но и у детей. Как правило, заболевание характерно для маленьких детей - чаще в возрасте до 5 лет, поскольку иммунитет у них еще недостаточно сформировался. Самый распространенный возбудитель стоматитов у малышей - вирус герпеса. У детей в 80 случаях из 100 стоматиты имеют герпетическое происхождение, причем дети могут заражаться как друг от друга, так и от взрослых. Возможна воздушно-капельная передача вируса [10, 12, 15].

Помимо вирусных стоматитов, выделяют травматические, которые у детей развиваются вследствие ожогов горячей пищей, прикусывания губ, щек, языка, повреждения слизистой оболочки игрушкой, карандашом или другими предметами. У детей постарше возбудителями становятся стрептококки и стафилококки. Распознать стоматит у детей несложно - на заболевание указывают покраснение и припухание СОПР, появление во рту болезненных пузырьков и/или язвочек, покрытых налетом, повышение температуры тела. На 2-й день болевые ощущения усиливаются, краснеют десны, появляются небольшие высыпания на коже вокруг рта и в его полости. Если стоматит протекает в тяжелой форме, он может сопровождаться повышением температуры тела до $40^{\circ} \mathrm{C}$ и множественными высыпаниями, причиняющими боль. У ребенка ухудшается состояние, снижается аппетит, так как прием пищи вызывает боль. Поэтому перед приемом пищи нередко рекомендуется смазать губы, язык, десны болеутоляющим средством.

Одно из самых известных заболеваний полости рта - инфекционный стоматит. Данное заболевание встречается достаточно часто как у взрослых, так и у детей. Им болеют $20 \%$ взрослого населения и 45\% детей от 6 месяцев. Правильная диагностика стоматита - достаточно сложный процесс по той простой причине, что явление стоматита может быть вызвано различными заболеваниями, которые способны протекать с одинаковыми явлениями. В настоящее время лечение стоматита по-прежнему остается актуальной проблемой медицины и фармации [7,18,19, 30].

Цель исследования: провести фармакоэкономический анализ спроса ассортимента лекарственных препаратов (ЛП) для лечения стоматита в аптечной организации (на примере аптечной сети «Аптечный дом»).
Материалы и методы. В ходе исследования использованы методы маркетингового анализа, АВС - анализ, контент-анализ.

Результаты и их обсуждение. На первом этапе исследования проведен сравнительный анализ ассортимента лекарственных препаратов для лечения стоматита на российском, региональном и локальном аптечном рынках. Установлено, что на региональном рынке представлено 98 лекарственных препаратов из 116 зарегистрированных в Российской Федерации. В аптечной сети «Аптечный дом»90 лекарственных препаратов для лечения стоматита. В связи с этим, необходимо расширить ассортимент ЛП для терапии данной нозологии в аптечной организации. Доля ЛП на российском, региональном и локальном рынке по АТХклассификация представлена идентичными группами, преобладают препараты группы R «Препараты, действующие на дыхательную систему». Так, на российском рынке группа $\mathrm{R}$ составляет $28 \%$, на региональном рынке - $23 \%$, на локальном $-22 \%$.

Анализ ассортимента ЛП для лечения стоматита на российском рынке показал, что ассортимент представлен в большей мере твердыми лекарственными формами (ЛФ) и содержит 43\%, на региональном рынке - $41 \%$, локальный рынок - 39\% от общего числа лекарственных форм.

Исследования

ассортимента по производственному признаку показали, что отечественные лекарственные препараты составляют 55\%. Детальный анализ зарубежных производителей выявил, что препараты Индии занимают 14\% импортного ассортимента. Ассортимент лекарственных препаратов для лечения стоматита отечественного производителя на региональном рынке составляет 53\%. Среди зарубежных производителей Великобритания занимает $16 \%$. Отечественные производители на локальном аптечном рынке занимают 52\%. Импортные лекарственные препараты представлены в большей мере Великобританией и занимают 19\%.

Ассортимент представлен, в основном, монокомпонентными лекарственными препаратами. Таким образом, составлен сравнительный контур ассортимента на всех трех рынках. 


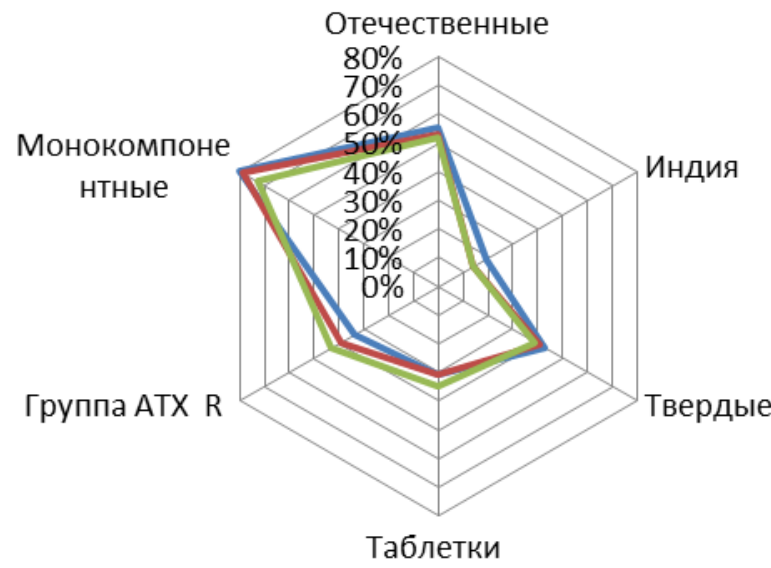

— Российский

— Региональный

— Локальный

Рис. 1. Сравнительный контур ассортимента для лечения стоматита российского, регионального и локального рынков, \%

Fig. 1. Comparative outline of the range of drugs for the treatment of stomatitis Russian, regional and local markets, $\%$

На втором этапе исследования проведен фармакоэкономический анализ ассортимента ЛП для лечения стоматита. Исследование ассортимента ЛП для лечения стоматита проводились на базе аптечной сети «Аптечный Дом», расположенной по адресу пр. Б. Хмельницкого, д. 103, аптека располагается в центре города, рядом с аптечной сетью находится остановка. Такое местоположение обуславливает широкий спектр посетителей различной категории, а вследствие этого, широкий ассортимент лекарственных средств.

Информационный массив для лечения стоматита реализованный аптечной сетью «Аптечный Дом» в период с апреля по ноябрь 2016 года, представлен 68 ЛП, данные препараты представлены 9 фармакологическими группами согласно АТХ-классификации и 116 международными непатентованными препаратами (МНH).
$\mathrm{ABC}$-анализ - метод, позволяющий классифицировать ресурсы компании по степени их важности. АВС-анализ опирается на правило Парето, утверждающим то, что только $20 \%$ элементов обеспечивают $80 \%$ результата. По отношению к формированию ассортимента правило Парето может прозвучать так: 20\% товарных позиций приносит $80 \%$ прибыли [3, $4,5,6]$.

В ходе исследования, проанализированы товарные отчеты за период с апреля по ноябрь 2016 года, для этого использовалась система управления, установленная в аптеке « М-Аптека Style». Параметром сегментирования ЛП для лечения стоматита на группы А, В и С выбран объем продаж за полугодие в рублях. Далее ассортимент лекарственных препаратов для лечения стоматита ранжирован в порядке убывания объема продаж за полугодие. 


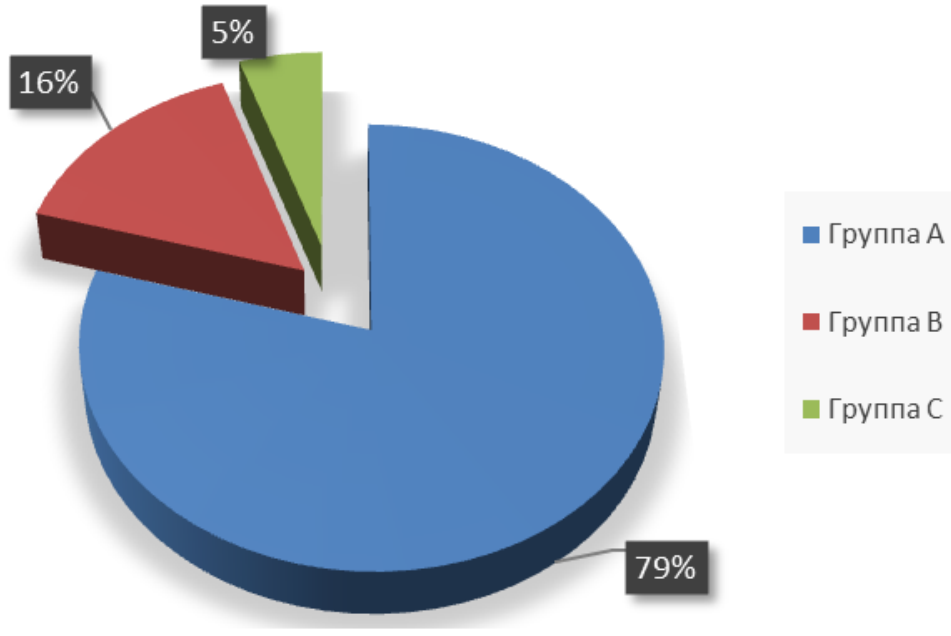

Рис. 2. Градация информационного массива по группам, \%

Fig. 2. Gradation information of the array by groups, $\%$

Установлено, что группа А составляет 36 наименований, занимает $20 \%$ ассортимента и приносит $80 \%$ прибыли от общего товарооборота среди лекарственных препаратов для лечения стоматита. К этой группе относятся ЛП: Мирамистин $0,01 \%$ p-p д/местного прим. 150 мл фл, Лизобакт таб. д/рассасывания 20 мг+10 мг №30, Тантум Верде спрей д/местного прим. 30 мл, Гексорал аэр. д/мест. Прим. 0,2\% фл.40 мл, Граммидин Нео с анестетиком таб. для рассасывания №18, Мирамистин 0,01\% p-p д/местного применения 50 мл, Имудон таб. д/рассывания №40, Мирамистин $0,01 \%$ p-p д/местного применения 50мл с распылителем, Граммидин Нео таб. д/рассасывания №18.

К группа В относятся 37 ЛП: Стрепсилс Интенсив таб. медово-лимонные № 24 д/рассасывания, Шалфей таб. д/рассасывания №20, Стопапгин спрей д/местного прим 0,2\% 30мл, Гексорал таб. д/рассасывания №20, Фарингосепт таб. д/рассасывания №10, Деринат p-p д/местного и наружного прим. $0,25 \%$ фл 10мл, Стрепсилс табл. с лимоном б/сахара №24 д/рассасывания, Ларипронт таб. д/рассасывания №20 и другие.

Группу C формируют 43 наименования: Фарингосепт таб. д/рассасывания №10 лимон, Деринат $\mathrm{p}-\mathrm{p}$ д/местного и наружного прим. $0,25 \%$ спрей 10мл, Офлоксацин таб/пл/о 400мг №10, Анти-ангин формула таб. д/рассасывания №20, Анти-ангин формула спрей д/местного прим. 25 мл, Пропосол спрей д/местного прим. 50 г, Сангвитриптин p-p д/мест и наружного прим. спирт $0,2 \% 50$ мл и другие.

Далее для подтверждения исследования проведен АВС - анализ методом сумм. Данный метод предполагает определение границ групп (A, В или С) по значению суммы двух показателей: доли продаж и доли по количеству с нарастающим итогом каждого проданного товара. Таким образом, суммарная доля равна 200\%. Группа А имеет границу до $100 \%$, группа В - до $145 \%$, группа С - всё оставшееся количество.

\section{Результаты АВС-анализа ассортимента методом сумм}

Таблица

The results of $\mathrm{ABC}$-analysis of assortment with the method of amounts

\begin{tabular}{|l|c|c|c|c|c|c|}
\hline \multicolumn{1}{|c|}{ Группа } & $\begin{array}{c}\text { Объем } \\
\text { продаж тыс. } \\
\text { рублей }\end{array}$ & $\begin{array}{c}\text { Доля в } \\
\text { обороте, \% }\end{array}$ & $\begin{array}{c}\text { Доля } \\
\text { куммулята, \% }\end{array}$ & $\begin{array}{c}\text { Доля } \\
\text { по кол- } \\
\text { ву, \% }\end{array}$ & $\begin{array}{c}\text { Доля } \\
\text { нарастаю-ву } \\
\%\end{array}$ & $\begin{array}{c}\text { Объем продаж } \\
+ \\
\text { доля } \\
\text { куммуляции, } \\
\%\end{array}$ \\
\hline А «Частопродаваемая» & 1031447,75 & 79,44 & $10,5-73,9$ & 0,862 & $0,8-24,9$ & $11,4-98,9$ \\
\hline В «Среднепродаваемая» & 203471,3 & 16,45 & $74,8-91,6$ & 0,862 & $25,8-52,5$ & $100,6-144,1$ \\
\hline С «Редкопродаваемая» & 80574,9 & 5,11 & $21,6-100$ & 0,862 & $53,4-100$ & $145,3-200$ \\
\hline Итого & 1315536 & 100 & & & & 200 \\
\hline
\end{tabular}


Установлено, что группа А занимает 100\% объема продаж от общего товарооборота. К этой группе относятся следующие наименования: Мирамистин 0,01\% p-р д/местного прим. 150 мл фл, Лизобакт таб. д/рассасывания 20мг+10 мг №30, Тантум Верде спрей д/местного прим. 30мл, Гексорал аэр. д/местного прим. 0,2\% фл.40мл и др.

Группа В формирует $144,18 \%$ от всего ассортимента и приносит до $45 \%$ дохода организации. К этой группе относятся ЛП: Стоматофит экстракт жидкий 100мл фл, Тантум Верде таб. д/рассасывания №20, Холисал гель стоматологический туба 15г, Стрепсилс таб. ментол-эвкалипт №24 д/рассасывания, Галавит таб. подъяыч. 25 мг №20 и др.

Препараты группы С дают $55 \%$ от общего дохода организации. К этой группе относятся ЛП: Асепта ополаскиватель 150 мл, Микосист капс. 150 мг, Бетадин p-p д/местного и наружного прим. $10 \%$ фл.30мл, Деринат p-p д/местного и наружного прим. $0,25 \%$ спрей 10 мл и др.

Заключение. Одним из важнейших условий эффективности деятельности организации розничной торговли является качественное управление товарными запасами, поэтому анализ состояния и эффективности использования товарных запасов являются необходимыми условиями для получения максимальной прибыли, так как они способствуют минимизации издержек на формировании и хранение запасов и росту объему продаж.

Таким образом, проведенный маркетинговый анализ показал, что

в аптечной сети отсутствуют 26 наименований препаратов, имеющихся на российском рынке, что ухудшает качество фармацевтической помощи.

Фармакоэкономические исследования показали, что лекарственные препараты, используемые для лечения стоматитов и входящие в группу А, приносят максимальную прибыль аптечной организации, поэтому их необходимо обязательно включать в портфель закупок при формировании ассортимента аптеки.

Состояние группы В необходимо постоянно анализировать, т.к. они могут переходить в группу А или С. Закупки этих ЛС должны быть обоснованы - по мере спроса, который необходимо стимулировать.

Спрос на товарные позиции, входящие в группу C необходимо стимулировать, а закупку этих ЛП ограничить. Самые неперспективные товарные позиции необходимо исключить из товарного запаса.
Соблюдения данных рекомендаций увеличит число лояльных покупателей и непременно повлечет за собой улучшение экономических показателей.

\section{Список литературы}

1. Абаджиди М.А., Лукушкина Е.Ф., Маянская И.В., Уровень цитокинов в секрете ротовой полости у детей с инфекционным стоматитом // Цитокины и воспаление. 2005. Т.1. №3. С. 9-14.

2. Анисимова И.В., Недосеко В.Б., Ломиашвили Л.М. Заболевание слизистой оболочки рта и губ. Учебное пособие: ООО «МЕДИиздательство» 2005. С. $45-46$.

3. Белоусов Е.А., Белоусова О.В., Трофимова В.Г. Изучение спроса на лекарственные препараты для лечения кожных заболеваний // Научный результат. Серия «Медицина и фармация» 2016. Т. 2. №1(7). C.59-63.

4. Белоусов Е.А., Белоусова О.В. Влияние маркетинговых подходов на комплексные продажи в аптеке // Научный результат. Серия «Медицина и фармация». 2015. №3(5). С.139-142.

5. Белоусова О.В., Белоусов Е.А., Лупандина Л.О. Анализ ассортимента гомеопатических средств на Российском фармацевтическом и аптечном рынках // Научный результат. Серия «Медицина и фармация». 2016. T.2. №2. С. 50-53.

6. Белоусова О.В., Белоусов Е.А., Иващенкова A.O. Биологически активные добавки как перспективное направление развития фармацевтического рынка // Научный результат. Медицина и фармация. 2016. Т.4. №4. С.89-94.

7. Гонтарев С.Н., Гонтарева И.С., Никишаева А.В. Использование фитопрепаратов в стоматологии детского возраста // Научный результат. Серия «Медицина и фармация». 2016. Т.2. №2. С.17-21.

8. Государственный Реестр лекарственных средств. Том 1. Официальное издание МЗ РФ 2004 года. М.: 2004. 1300c.

9. Изменения в полости рта у детей при общесоматических заболеваниях : учеб.пособ. под ред. Е.В. Удовицкой. М.: ЦИУВ, 1982. С. 22-24.

10. Камышникова Л.А., Ефремова О.А., Гусейнли Э.Г. Современный обзор: Helicobacter pylori и риск развития ишемической болезни сердца // Научный результат. Медицина и фармация. 2016. Т.2. №3. С.3-9.

11. Лопатин А.C. Топические лизаты: опыт применения в оториноларингологии. А.С. Лопатин // Лечащий врач.2006. №4. С.7-8.

12. Лукиных Л.М. Заболевания слизистой оболочки полости рта. Нижний Новгород, 2000. 367 с.

13. Назаров П.Г. Воспаление: локальные и системные механизмы защиты слизистых оболочек // Новости оториноларингол. Логопатол. 2009. №2(26). C. 39-41.

14.Новиков О.О., Жилякова Е.Т., Цимбалистов А.В., Трифонов Б.В., Малютина А.Ю., Писарев Д.И. Новый взгляд на проблему профилактики и лечения 
заболеваний пародонта // Научный результат. Медицина и фармация. 2016. Т.2. №3. С.65-69.

15. Пальчун В.Т. В борьбе за здоровый рот // Фармацевтический вестник. 2007. №39. С. 27-28.

16. Рабинович И.М. Рецидивирующий афтозный стоматит. Клиника, диагностика, лечение // Клиническая стоматология. 1998. №3. С. 26-28.

17. Рыбаков А.И., Банченко Г.В. Заболевания слизистой оболочки полости рта. - М.: Медицина. 2008. C. 2-4.

18. Сборник научных тезисов и статей «Здоровье и образование в XXI веке» РУДН, Москва, 2010. С. 35-47.

19. Семенова Т.Б., Губанова Е.И. Современные представления о клинике, особенностях, эпидемиологии и лечении простого герпеса // Лечащий врач. 1999. №2-3. С. 10-16.

20. Сепетлиев Д. Статистические методы в научных медицинских исследованиях. М.: Медицина, 1968. С. 125-258.

21. Солдатов И.Б. Руководство по оториноларингологии. - М.: Медицина. 2009. 288c.

22. Спицына В.И. Особенности иммунодефицита у больных рецидивирующим афтозным стоматитом // Российский стоматологический журнал. 2006. № 4. С. 14-18.

23. Трезубов В.Н., Щербаков А.С., Мишнев Л.М.. Ортопедическая стоматология. СПб.: Фолиант, 2002. C. 385-387.

24. Цветкова Л.А., Арутюнов С.Д., Петрова Л.В., Перламитров Ю.Н. Заболевания слизистой оболочки полости рта и губ. - М.: МЕДпресс-информ. 2005. C. 35-37.

25. Чемикосова T.C. О предупреждении обострений рецидивирующего афтозного стоматита // Казанский Медицинский Журнал. 2003. Т.84. №4. C. 267-269.

26. Шеврыгин Б.В. Болезни ЛОР-органов: профилактика // Факультет здоровья. 2008. №415. C. 13-15.

27. Shulman J.D., Beach M.M., Rivera-Hidalgo F. The prevalence of oral mucosal lesions in U.S. adults. Data from the third National Health and Nutrition Examination Survey, 1988-1994. J Am Dent Assoc. 2004.№ 135. Pp. 1279-1286.

28. Shulman J.D., Rivera-Hidalgo F., Beach M.M. Risk factors associated with denture stomatitis in the United States. J Oral Pathol Med. 2005.T 34. Pp. 340-346.

29. Van Joost T., van Ulsen J., van Loon L.A.Contact allergy to denture materials in theburning mouth syndrome. Contact Dermatitis. 1988 №18. Pp. 97- 99.

30. Vigild M. Oral mucosal lesions among institutionalized elderly in Denmark. Community Dent Oral Epidemiol. 1987. №15.Pp.309-313.

31. Walter B., Frank R.M. Ultrastructural relationship of denture surfaces, plaque and oral mucosa in denture stomatitis. J Biol Buccale. 1985.№ 13.Pp. 145-166.

\section{References}

1. Abadzhidy M.A., Lukushkina E.F., Mayanskaya I.V. The level of cytokines in the oral cavity secretion in children with infectious stomatitis. Cytokines and inflammation. 2005. Vol.1. №. 3. Pp. 9-14.

2. Anisimov V.I., Nedoseko V.B., Lomiashvily L.M.. Disease of the mucous membrane of the mouth and lips. Textbook. OOO "Mediendienste" 2005, Pp. 45-46.

3. Belousov E.A., Belousova O.V., Trofimova V.G. The study of the demand for drugs for the treatment of skin diseases. Research Result. Series "Medicine and pharmacy". 2016. Vol. 2. №. 1(7). Pp. 59-63.

4. Belousov E.A., Belousova O.V. The Impact of marketing approaches on a complex sale in the drugstore. Research result. Series "Medicine and pharmacy". №3(5). 2015. Pp. 139-142.

5. Belousova O.V., Belousov E.A., Lupandin L.O. Analysis of the range of homeopathic medicines on the Russian pharmaceutical and pharmacy markets. Research result. Series "Medicine and pharmacy". 2016. Vol. 2. №.2. Pp. 50-53.

6. Belousova O.V., Belousov E.A., Ivashenkova A.O. Dietary supplements as a perspective direction of development of the pharmaceutical market. Research result. Medicine and pharmacy. 2016. Vol.4. №.4. Pp.89-94.

7. Gontarev S.N., Gontareva I.S., Nikishaeva A.V. The use of herbal medicine in stomatology of children's age. Research result. Series "Medicine and pharmacy".. 2016. Vol. 2, №. 2. Pp.17-21.

8. The State Register of Medicines. Volume 1. The official publication of the Ministry of health of the Russian Federation 2004. M.: 2004. 1300p.

9. Changes in the oral cavity in children with somatic diseases: a textbook. manual. Ed. By E.V. Udovicki. M.: CYUV, 1982. Pp.22-24.

10. Kamyshnikova L.A., Efremova O.A., E.G. Huseynli Modern overview: Helicobacter pylori and the risk of coronary heart disease. Research result. Medicine and pharmacy. 2016. Vol.2. №.3. Pp.3-9.

11. Lopatin A.S. Topical lysates: practices in otolaryngology. Doctor.2006. №.4. P. 7-8.

12. Lukinykh L.M. diseases of the mucous membranes of the mouth. Nizhny Novgorod, 2000. 367 p.

13. Nazarov P.G. Inflammation: local and systemic defense mechanisms of the mucous membranes. News otorinolaringol. Throat. 2009. №2 (26). Pp. 39-41.

14. Novikov O.O., Zhilyakova E.T., Tsimbalistov A.V., Trifonov B.V., Malyutina A.Yu., Pisarev, D.I. A New approach to the problem of prevention and treatment of periodontal disease. Research result. Medicine and pharmacy. 2016.Vol.2, №3. Pp.65-69.

15. Palchun V.T. In the fight for a healthy mouth. Pharmaceutical Bulletin. 2007. №39. P. 27-28.

16. Rabinovich I.M. Recurrent aphthous stomatitis. Clinic, diagnostics, treatment. Of clinical dentistry. 1998. №. 3. Pp. 26-28.

17. Rybakov A.I., Panchenko G.V. Diseases of the mucous membranes of the mouth. M.: Medicine. 2008. Pp. 2-4. 
18. Collection of scientific articles "Health \& education in the XXI century" RUDN, Moscow, 2010.Pp.35-47.

19. Semenova T.B., Gubanova E.I. Modern views on the clinic, characteristics, epidemiology and treatment of herpes simplex. Doctor. 1999. №2-3. Pp. 10-16.

20. Sepelev D. Statistical methods in the scientific medical research. M.: Medicine, 1968. Pp. 125-258.

21. Soldatov I.B. Manual of otorhinolaryngology. M.: Medicine. 2009. 288p.

22. Spitsyn V.I. The peculiarities of immunodeficiency in patients with recurrent aphthous stomatitis. Russian stomatological journal. 2006. №. 4. Pp. 14-18.

23. Trezubov V.N., Shcherbakov A.S., Mishnev L.M. Prosthetic dentistry. SPb.: Foliant, 2002. Pp. 385-387.

24. Tsvetkova L.A., Arutyunov S.D., Petrova L.V., Perlamutrov Yu.N. Diseases of the mucous membranes of the mouth and lips. M.: Medpress-inform. 2005. P. 35-37.

25. Chemikosova T.S. On the prevention of exacerbations of recurrent aphthous stomatitis. Kazan Medical Journal. 2003. Vol. 84. №.4. Pp. 267-269.

26. Shevrygin B.V. Diseases of the respiratory tract: prevention. The Department of Health. 2008. №415. Pp.13-15.

27. Shulman J.D., Beach M.M., Rivera-Hidalgo F. The prevalence of oral mucosal lesions in U.S. adults. Data from the third National Health and Nutrition Examination Survey, 1988-1994. J Am Dent Assoc. 2004.№ 135. Pp. 1279-1286.
28. Shulman J.D., Rivera-Hidalgo F., Beach M.M. Risk factors associated with denture stomatitis in the United States. J Oral Pathol Med. 2005.T 34. Pp. 340-346.

29. Van Joost T., van Ulsen J., van Loon L.A.Contact allergy to denture materials in theburning mouth syndrome. Contact Dermatitis. 1988 №18. Pp. 97- 99.

30. Vigild M. Oral mucosal lesions among institutionalized elderly in Denmark. Community Dent Oral Epidemiol. 1987. №15.Pp.309-313.

31. Walter B., Frank R.M. Ultrastructural relationship of denture surfaces, plaque and oral mucosa in denture stomatitis. J Biol Buccale. 1985.№ 13.Pp. 145-166.

Белоусова Ольга Викторовна, доцент кафедры управления и экономики фармации, кандидат фармацевтических наук

Белоусов Евгений Александрович, старший преподаватель кафедры управления и экономики фармации, кандидат фармацевтических наук

Дорохова Наталья Николаевна

студентка 5 курса Медицинского института, специальности «Фармация»

Belousova Olga Viktorovna, $\mathrm{PhD}$ in Pharmaceutical Sciences, Associate Professor, Department of Management and Economics

Belousov Yevgeny Aleksandrovich, $\mathrm{PhD}$ in Pharmaceutical Sciences, Senior Lecturer, Department of Management and Economics

Dorokhova Natalia Nikolaevna, $5^{\text {th }}$-year Student, Medical Institute 